\title{
MOODLE LMS Resources Prediction: Exponential Moving Average Approach
}

\author{
Marcel Bonar Kristanda ${ }^{1}$, Seng Hansun ${ }^{2}$ \\ ${ }^{1}$ Informatics Department, Universitas Multimedia Nusantara, Tangerang, Indonesia, marcel.bonar@umn.ac.id \\ ${ }^{2}$ Informatics Department, Universitas Multimedia Nusantara, Tangerang, Indonesia, hansun@umn.ac.id
}

\begin{abstract}
Learning Management System (LMS) is a software that helps higher education institution provide their services to teachers and students. Every year intakes in the university aim to take more students to register. This phenomenon impacts LMS data storage capacity. University has to find a strategy in identifying how much size they need to prepare. One way to identify it is by using an exponential moving average method to predict storage that needed in the further semester. Tested with a web forecasting application and Universitas Multimedia Nusantara's Moodle dataset, exponential moving average was giving a big error measurement number. This means that the exponential moving average was not quite fit to predict the resources in LMS.
\end{abstract}

Key words: EMA, LMS, MOODLE, Resources Prediction

\section{INTRODUCTION}

Higher education institutions have been utilizing E-Learning services by providing Learning Management System (LMS) for lecturers and students to support teaching and learning process [1]. This system leads to a need where Information Technology (IT) resources play an important role to satisfy students' learning experiences [2]. Lecturers and students are accessing those resources from a wide variety of learning activities in many LMS features [3].

Since the beginning of the 21 st century, there are several concerns regarding the increasing number of resources that correlates with the size of data stored inside the database through learning object repositories [4]. The management of multiple data storage centers may require to maintain IT services and applications in which LMS is included [5]. Scalability issues of LMS also motivate researchers in finding alternative data integrations strategy with third-parties services [6]. More students each intake means more accounts and storage size prepared for them and their lecturers.

Investing in such incremental trend-based IT resources must involve a strategy that leads to cost-effective challenges for the institution [7]. Some of the well-known universities have been doing a strategy in providing storage and LMS server for each study year (one study year, one server) [8]-[11]. In this case, the university has to identify how much storage size required for each study year that involves several factors like student intakes, curriculum and learning materials development and changes, graduations, class management and any other factors that will impact data storage for LMS resources.

Forecasting the amount of storage size is one of many ways that can be used in identifying data storage size need for operating LMS each year. Many fields use forecasting techniques to predict data based on time-series dataset [12]. In information system management, forecasting methods are in line with the purpose to allocate resources effectively [13]. Moreover, forecasting technique called exponential moving average has proven its capabilities in predicting data storage server performance [14].

This research proposed a study on utilizing exponential moving average (EMA) method to predict LMS resources. Courses held in Universitas Multimedia Nusantara (UMN) who runs LMS based on Moodle Platform. The capabilities of the prediction method analysis evaluated on three forecast error measurements as can be found in Section 3.

\section{MOODLE LMS}

Learning Management System (LMS) is software that tackles a wide variety of tasks in the administrative context and provides features that support interactive learning process [3]. There are several kinds of LMS from open sources to proprietary one.

Moodle is an open-source LMS recognized as one of the top E-Learning solutions for teachers and students [15], [16]. There are three parts of features in this LMS from General, Administrative and Course Development and Management [17]. Part of this LMS that took resources mostly is the Course Development and Management, where the learning object repositories lies in. Moodle has been observed as one of the LMS that has complete capabilities and accessibility [18].

Moodle has a range of resources that can be used to help teachers in delivering their courses. Moodle's resources will appear as a link with an icon which represents the resource's type, such as File, Folder, Book, Label, Page, IMS content package, and URL [19]. An example for Moodle's User Interface is shown figure 1 . 


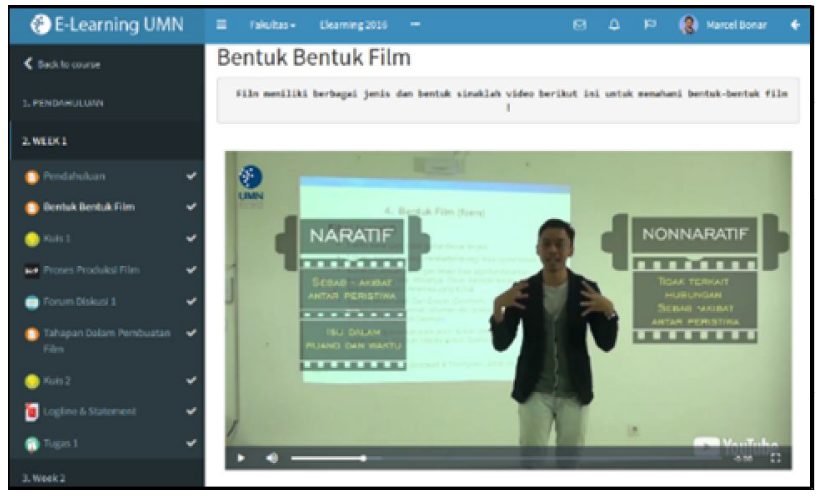

Figure 1: Example of Moodle's User Interface

\section{EXPONENTIAL MOVING AVERAGE AND ERROR MEASUREMENTS}

\subsection{EMA}

EMA is a popular forecasting method that could smooth random fluctuations. Although it puts greater weight to recent data just like WMA, the weighting factor function is an exponential. As can be seen in Hansun et al. [20], we can calculate EMA for time series $Y$ using:

$$
\begin{gathered}
S_{1}=Y_{1} \\
\text { for } t>1, S_{t}=\alpha \cdot Y_{t}+(1-\alpha) \cdot S_{t-1}
\end{gathered}
$$

where $Y_{t}$ is the value at a time period, $S_{t}$ is EMA value, and $\alpha$ is the constant smoothing factor which ranged 0 to 1 . As can be seen in [21], we can estimate $\alpha$ as:

$$
\alpha=\frac{2}{n+1}
$$

In this research, we try to search for the best $\alpha$ value, which minimizes the error rate by using a brute force approach. Three well-known forecast error measurements also will be explained here, i.e., mean square error (MSE), mean absolute percentage error (MAPE), and mean absolute scaled error (MASE). These measurements will be used to estimate the quality of forecasting methods implemented in this study.

\subsection{MSE}

MSE is the squared error sum average of the forecasted data with the actual one. MSE can be calculated using [22]:

$$
M S E=\frac{1}{n} \sum_{t=1}^{n}\left(A_{t}-F_{t}\right)^{2}
$$

where $n$ refers to the total number of data, $A_{t}$ is the actual value, and $F_{t}$ is the forecasted value.

\subsection{MAPE}

MAPE is the absolute error sum average of the forecasted and real data, divided by the real data. As described by Alsultanny [22], MAPE can be found using:

$$
M A P E=\left(\frac{1}{n} \sum_{t=1}^{n}\left|\frac{A_{t}-F_{t}}{A_{t}}\right|\right) \cdot 100 \%
$$

where $n$ refers to the number of data, $A_{t}$ is the actual value, and $F_{t}$ is the forecasted value. In MAPE, the accuracy is expressed as a percentage.

\subsection{MASE}

MASE is a relatively new method to calculate forecast error that was proposed by Hyndman and Koehler in [23]. It scales errors based on the in-sample mean absolute error (MAE) from the naïve forecasting method [24]-[25], and can be expressed as:

$$
M A S E=\operatorname{mean}\left(\left|\frac{A_{t}-F_{t}}{Q}\right|\right)
$$

where $A_{t}$ is the actual value of data, $F_{t}$ is the forecasted value, and $Q$ is a measure of the scale of the time series calculated on the training dataset, which can be found using [26]:

$$
Q=\frac{1}{n-1} \sum_{i=2}^{n}\left|A_{i}-A_{i-1}\right|
$$

for non-seasonal time series data, and

$$
Q=\frac{1}{n-1} \sum_{i=2}^{n}\left|A_{i}-A_{i-1}\right|
$$

for seasonal time series data. Here $m$ is the season length.

\section{RESULTS}

\subsection{Dataset}

Dataset for prediction test gathered from Moodle that runs by Universitas Multimedia Nusantara in elearning.umn.ac.id. It takes a total of 636 time-series data rows of resources usage that gathered from 17 July 2014 to 28 September 2019.

Dataset filtered by eliminating the null value and repair date-time formatting to fulfill the required format in the testing process using a web application called Phatsa.

\subsection{Test Phase}

First, the user should choose which method they want to use. There are three different options, i.e., SMA, WMA, and EMA. However, there are several required parameters here, i.e.

- Span Data, i.e., the numerical period value in a positive integer.

- Start Index, i.e., the first index in the dataset where the prediction begins.

- Prediction Period, i.e., the period count that user wants to predict.

In the next step, users are required to upload a formatted CSV file under the following rules:

- There are two columns of data and no limitations on row numbers.

- The first row contains the two labels, i.e., "Period" and "Value." 
- Below the first row are any historical data that will be used in the calculation.

After successful submission of the file, the application calculates all data, and later, it shows original and predicted dataset as shown in Figure 2. The application also displays six calculation results, i.e., MSE, MAPE, MASE, Calculating Average Time, Calculating Error Time, and Overall Calculating Time.

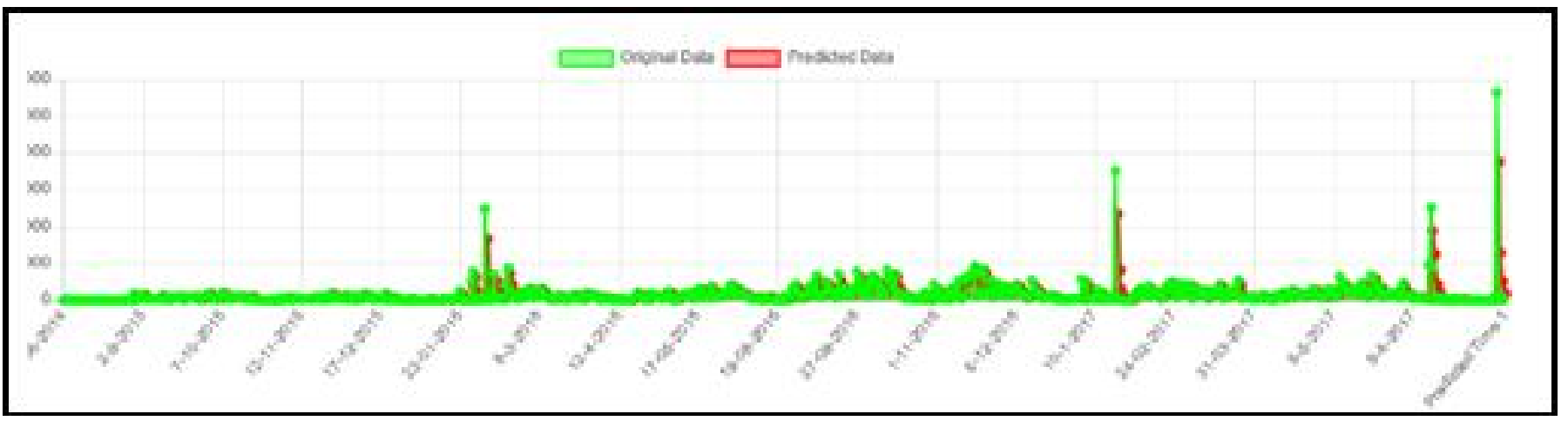

Figure 2: Prediction Results

\subsection{Results}

Table 1: Error Measurements from EMA calculation of LMS Resources

\begin{tabular}{ccc}
\hline MSE & MAPE & MASE \\
\hline $\begin{array}{c}5978474382246900 \\
00\end{array}$ & 15930.858435489 & 31.933733592296 \\
\hline $\begin{array}{c}\text { Calculating Average } \\
\text { Time }\end{array}$ & $\begin{array}{c}\text { Calculating Error } \\
\text { Time }\end{array}$ & $\begin{array}{c}\text { Overall } \\
\text { Calculating Time }\end{array}$ \\
\hline 0.0292 & 0.0005 & 0.0297 \\
\hline
\end{tabular}

Given results in Table 1 shows a high error rate number from the dataset processed through the exponential moving average method. Even though it shows calculating time below one second, this result shows that exponential moving average is not capable of predicting LMS resources.

\section{CONCLUSION}

The exponential moving average has been proven to perform monitoring and analysis report in several LMS server. This study shows that the forecasting method can't identify the necessity of data storage size that increased every time in LMS for university. Dynamically seasonal data like semester break, holidays, and short semester distract the method implementation in predicting the storage size needed for next semester, or even next study year.

For future researches, other prediction methods such as ARIMA and Backpropagation ANN can be done. Both of them have successfully been applied in other case studies, as we can see in [27-28].

\section{ACKNOWLEDGEMENT}

This study has been supported and funded by Kemenristekdikti through the 'Penelitian Produk Terapan' Grant (Contract Number 425/LPPM-UMN/IV/2017).

\section{REFERENCES}

1. F. J. García-Peñalvo and M. Alier Forment. Learning management system: evolving from silos to structures, Interact. Learn. Environ., vol. 22, no. 2, pp. 143-145, Mar. 2014. https://doi.org/10.1080/10494820.2014.884790

2. A. Horvat, M. Dobrota, M. Krsmanovic, and M. Cudanov. Student perception of Moodle learning management system: a satisfaction and significance analysis, Interact. Learn. Environ., vol. 23, no. 4, pp. 515-527, Jul. 2015. https://doi.org/10.1080/10494820.2013.788033

3. P. Barge and B. R. Londhe. From Teaching, Learning to Assessment: MOODLE Experience at B'School in India, Shap. Future Bus. Soc., vol. 11, no. Supplement C, pp. 857-865, Jan. 2014. https://doi.org/10.1016/S2212-5671(14)00249-4

4. S. Downes, O. Shata, F. O. Lin, and M. Jamlan. Learning Objects: Resources for Distance Education Worldwide [and] Critiques of Stephen Downes Learning Objects, Int. Rev. Open Distance Learn., vol. 2, no. 1, p. n1, 2001. https://doi.org/10.19173/irrodl.v2i1.32

5. K. Oh, A. Raghavan, A. Chandra, and J. Weissman. Redefining Data Locality for Cross-Data Center Storage, in Proc. of the 2nd International Workshop on Software-Defined Ecosystems, Portland, Oregon, USA, 2015, pp. 15-22.

6. R. Ferdiana. The comparison of consumer cloud storage for a storage extension on the e-learning, in Proc. of 2016 6th International Annual Engineering Seminar (InAES), 2016, pp. 182-186.

https://doi.org/10.1109/INAES.2016.7821930 
7. M. P. J. Mahenge, J. Mwangoka, and F. Simba. Cost-effective mobile based learning content delivery in resources and network constrained environments, in Proc. of the 2nd Pan African International Conference on Science, Computing and Telecommunications (PACT 2014), 2014, pp. 165-170. https://doi.org/10.1109/SCAT.2014.7055153

8. "UCL Moodle Snapshot." [Online]. Available: https://moodle-snapshot.ucl.ac.uk/.

9. "Moodle Archive for 2015-16." [Online]. Available: https://moodlearchive.essex.ac.uk/2015/.

10. "Moodle Archive (2015-16)." [Online]. Available: http://moodlearch.port.ac.uk/2015/.

11. "Moodle - E-Learning - University of Kent." [Online]. Available: https://www.kent.ac.uk/elearning/moodle/.

12. P. J. Brockwell and R. A. Davis. Introduction to time series and forecasting. Springer, 2016. https://doi.org/10.1007/978-3-319-29854-2

13. R. Hu, J. Jiang, G. Liu, and L. Wang. Efficient resources provisioning based on load forecasting in cloud, Sci. World J., vol. 2014, 2014. https://doi.org/10.1155/2014/321231

14. T. Li and $\mathrm{R}$. Zhou. Method and apparatus for big data cloud storage resource management. Google Patents, 2016.

15. "Top 20 LMS Software 2017 - Compare Reviews." [Online]. Available: https://www.capterra.com/learning-management-system -software/.

16. "The 20 Best Learning Management Systems (2017 Update)," eLearning Industry, 18-Jan-2014. [Online]. Available:

https://elearningindustry.com/the-20-best-learning-mana gement-systems.

17. "Features - MoodleDocs." [Online]. Available: https://docs.moodle.org/33/en/Features.

18. M. Ş. Kuran, J. M. Pedersen, and R. Elsner. Learning Management Systems on Blended Learning Courses: An Experience-Based Observation, in Image Processing and Communications Challenges 9: 9th International Conference, IP\&C'2017 Bydgoszcz, Poland, September 2017, Proceedings, M. Choraś and R. S. Choraś, Eds. Cham: Springer International Publishing, 2018, pp. 141-148.

19. "Resources - MoodleDocs." [Online]. Available: https://docs.moodle.org/33/en/Resources.

20. S. Hansun, M. B. Kristanda, Winarno. Central Jakarta Air Quality Forecast based on PM2.5, International Journal of Innovative Technology and Exploring Engineering, vol. 8, no. 6C2, pp.158-165, 2019.

21. S. Hansun and M. B. Kristanda. Major FX Forecasting with Hybrid Moving Average Approach, International Journal of Engineering \& Technology, vol. 7, no. 4.40, pp. 108-111, 2018. https://doi.org/10.1109/ITNG.2012.160

22. Asultanny Y. Successful Forecasting for Knowledge Discovery by Statistical Methods, in Proc. of $9^{\text {th }}$ International Conference on Information Technology: New Generations, Las Vegas, USA, 2012, pp. 584-588.
23. S. Hansun, V. Charles, C. R. Indrati, and Subanar. Revisiting the Holt-Winters' Additive Method for Better Forecasting, International Journal of Enterprise Information Systems, vol. 15, no. 2, pp. 43-57, 2019. https://doi.org/10.4018/IJEIS.2019040103

24. R. J. Hyndman and A. B. Koehler. Another Look at Measures of Forecast Accuracy, International Journal of Forecasting, vol. 22, no. 4, pp. 679-688, 2006. https://doi.org/10.1016/j.ijforecast.2006.03.001

25. R. J. Hyndman. Another Look at Forecast-Accuracy Metrics for Intermittent Demand, Foresight: The International Journal of Applied Forecasting, vol. 4, pp. 43-46, 2006. https://doi.org/10.1016/j.ijforecast.2006.03.001

26. R. J. Hyndman and G. Athanasopoulos. Forecasting: Principles and Practice. Melbourne, Australia: Otexts, 2013.

27. E. P. Patulin and R. E. Talingting. Crime Prediction using Autoregressive Integrated Moving Average (ARIMA) Algorithm, International Journal of Advanced Trends in Computer Science and Engineering, vol. 8. No. 3, pp. 720-724, 2019. https://doi.org/10.30534/ijatcse/2019/59832019

28. M. K. Singla, J. Gupta, and P. Nijhawan. Comparative Study on Backpropagation and Levenberg Marquardt Algorithm on Short Term Load Forecasting, International Journal of Advanced Trends in Computer Science and Engineering, vol. 8. No. 2, pp. 194-202, 2019 https://doi.org/10.30534/ijatcse/2019/14822019 